\title{
The Vitreoretinal Interface in Retinal Vein Occlusions - A Clue for Surgery?
}

\author{
Simon Brunner
}

Ophthalmologist, Department of Ophthalmology, The Rudolph Foundation Hospital, Vienna, Austria

\begin{abstract}
Retinal vein occlusions are still one of the leading retinal vasculopathies with a strong impact on the quality of life. Despite the success in symptomatic treatment with anti-vascular endothelial growth factor (VEGF) medication, no real causal therapy has been developed so far. As most of the pathogenetic changes have been observed in the vitreoretinal interface, actual therapeutic strategies are being focused on this area. Modern surgical techniques may help to release vitreovascular traction, stop cytokine activation and improve retinal oxygenation.
\end{abstract}

\section{Keywords}

Retinal vein occlusions, central retinal vein occlusion, branch retinal vein occlusion, vitreoretinal interface, vitreoretinal surgery, vitrectomy surgery

Disclosure: Simon Brunner has nothing to disclose in relation to this article. There were no publication fees associated with this article.

Open Access: This article is published under the Creative Commons Attribution Noncommercial License, which permits any non-commercial use, distribution, adaptation and reproduction provided the original author(s) and source are given appropriate credit.

Received: 23 November 2015 Published Online: 21 December 2015 Citation: European Ophthalmic Review, 2015;9(2):138-40

Correspondence: Simon Brunner, The Rudolph Foundation Hospital, Department for Ophthalmology, Juchgasse 25, A-1030 Vienna, Austria; E: simon.brunner@wienkav.at

Retinal vein occlusions (RVO) affect over 16 million people worldwide, with 2.5 million affected by central retinal vein occlusions (CRVO) and 13.9 million affected by branch retinal vein occlusions (BRVO). ${ }^{1}$ RVO are still the second leading retinal vasculopathy after diabetic retinopathy and the fifth leading cause of monocular blindness. ${ }^{2}$ Up to $15 \%$ of patients are younger than 50 years, pointing to a strong impact on quality of life as well as on economic burden, especially for patients affected by CRVO. ${ }^{3,4}$

Current evidence suggests two main unquestionable principles of therapy: first, the reduction of macular oedema (MO), venostasis and extravasation of cytokines and other blood components by multiple administrations of intravitreal anti-angiogenetic medication (IVAM, such as vascular endothelial growth factor [VEGF]-inhibitors) in the short- and mid-term; and, second, the recognition and treatment of cardiovascular risk factors, especially for CRVO patients, in the long term. ${ }^{5,6}$

Unfortunately, no real causal therapy for RVO has been developed so far. However, most of the pathogenetic changes following RVO are observed in a region called the vitreoretinal interface (VRI): extravasation of cytokines, growth factors and other blood components, secondary inflammatory processes and the breakdown of the blood-retina barrier. Anatomically, the VRI consists of the posterior vitreous cortex, the inner limiting membrane (ILM) and an intervening extracellular matrix.

Consequently, several new surgical strategies targeting the VRI have been developed to overcome the need for repeated intravitreal injections over months and years, and to optimally reduce the risk of late local or systemic complications.

\section{Anatomic Role of the Vitreoretinal Interface}

It has been observed that the ILM is much thinner in the regions close to the retinal vasculature. Moreover, a strong adhesion of vitreous with blood vessels does exist with a tendency for traction, vascular leakage, neovascularisation (NV) and haemorrhage. ${ }^{8,9}$ In a prospective case-control study, vitreovascular traction at the occlusion site was significantly associated with BRVO. ${ }^{10}$ Similarly, other studies showed a higher incidence for $\mathrm{MO}$ or NVs in eyes with vitreomacular adhesions after BRVO or CRVO, respectively. ${ }^{11,12}$ Therefore an attached posterior vitreous cortex with or without traction may play a pathogenetic role in RVO.

In fact, the induction of a posterior vitreous detachment (PVD) with or without plasmin seems to protect against retinal or optic disc NV in severe CRVO, ${ }^{11}$ increases vitreal oxygen levels via microplasm ${ }^{13}$ and may improve acuity and reduced $\mathrm{MO}$ in BRVO. ${ }^{14}$ Pars-plana vitrectomy alone can also improve acuity and/or MO in RVO by removing blood components, vitreomacular traction and the scaffold for later NV15,16 (see Figure 1).

Vitrectomy may be combined with ILM peeling with significant anatomic and functional improvements. ${ }^{17}$ Further additional tools include radial optic neurotomy (RON) at the level of the lamina cribrosa in CRVO (see Figure 2) or adventitial sheathotomy at the arteriovenous crossing site in BRVO. Whereas RON has proved a significantly better anatomical and functional outcome in several randomised trials, ${ }^{18,19}$ adventitial sheathotomy showed only a small, if any, benefit - if compared with standard vitrectomy or IVAM therapy. ${ }^{20,21}$

RON seems also to protect patients from anterior $\mathrm{NV}$; however, this technique is more invasive and risky than routine vitrectomy procedure..$^{22}$ 


\section{Figure 1: Vitreomacular Traction in BRVO}
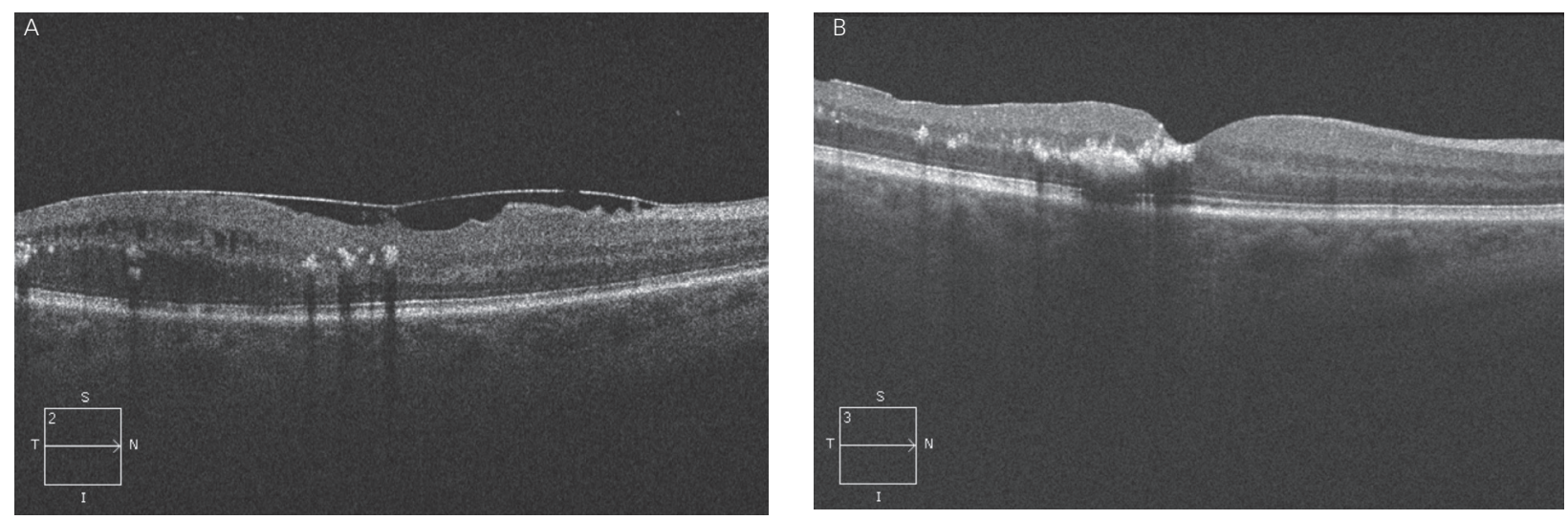

A. Vitreomacular traction in branch retinal vein occlusion (BRVO) with cystoid macular oedema and hard retinal exudates. B. Same patient after successful vitrectomy surgery with resolved macular oedema.

\section{Figure 2: Principle of Radial Optic Neurotomy}

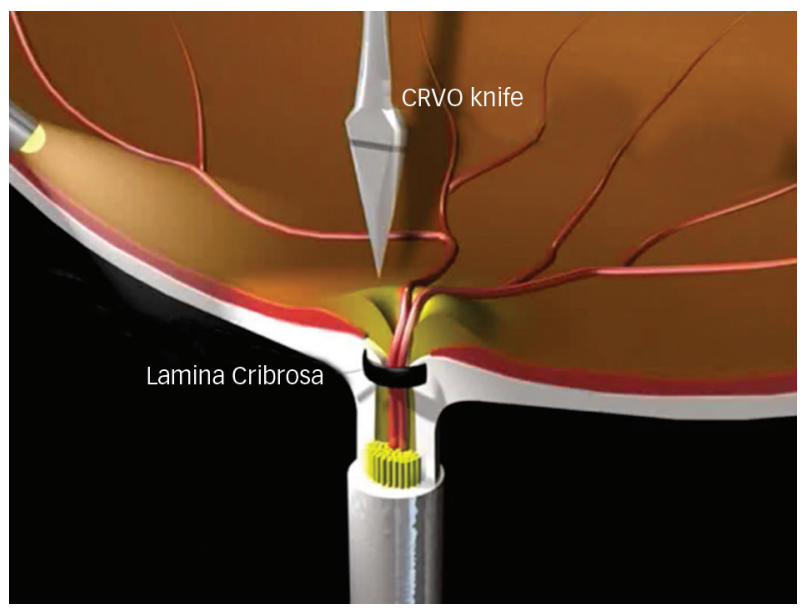

The specially designed radial optic neurotomy knife has a sharp and a blunt edge. The blunt edge is directed towards the vessels. CRVO = central retinal vein occlusion.

\section{Cytokine Activation in the Vitreoretinal Interface}

Ischaemia of the inner retinal layers in RVO leads to a massive and sustained upregulation and secretion of multiple growth factors and cytokines, such VEGF-A, intercellular adhesion molecule 1 (ICAM1), interleukin (IL)-1, IL-6, pigment epithelium-derived factor (PEDF), monocyte chemotactic protein-1 (MCP-1), aquaporin-1 (Aqp-1), Aqp-4, pentraxin-3 (PTX-3) and plasminogen into the VRI, and the activation of other factors, as matrix metalloproteinase-2 (MMP-2), MMP-9, tightjunction protein (ZO-1) and occludin on the endothelial surface ${ }^{23,24}$; see Figure 3. In longer-standing CRVO of a duration over 7 months, only MCP-1 is still significantly elevated, pointing out to monocyte recruitment to the vessel wall in the later course of the disease. ${ }^{25}$ Furthermore, all vitreous cytokine levels are significantly correlated with central retinal thickness and the severity of $\mathrm{MO}$, determined by optical coherence tomography (OCT) ${ }^{26,27}$ (see Figure 1).

Therefore, state-of-art therapy is mainly focused on repeated intravitreal injections of anti-inflammatory medication, primarily anti-VEGF antibodies, to counteract the cascade of inflammatory mediators. ${ }^{28}$ Unfortunately, this therapy is needed regularly (monthly) over a rather long time period, similar to the treatment of neovascular age-related macular degeneration (AMD). To overcome the need for frequent injections, intravitreal steroid implants with a longer half-life have been
Figure 3: Diagram Depicting the Massive Elevation of Cytokines in BRVO Patients

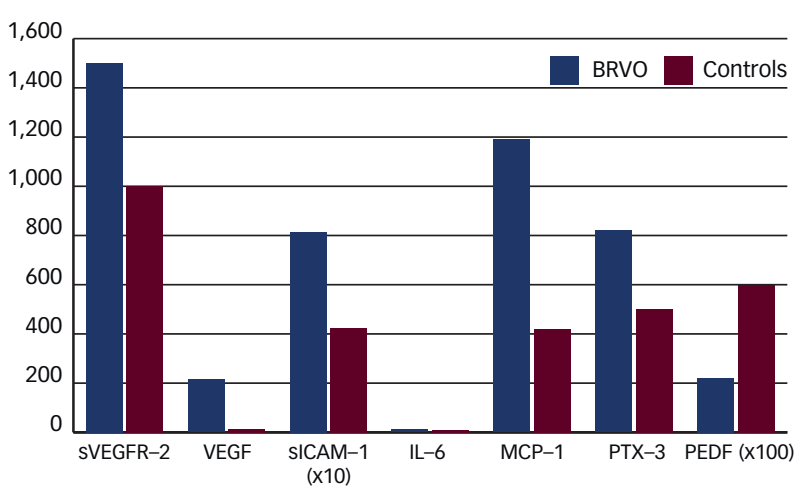

BRVO = branch retinal vein occlusion; ICAM-1 = intercellular adhesion molecule $1 ; \mathrm{IL}-6=$ interleukin-6; MCP-1 = monocyte chemotactic protein-1; PEDF = pigment epitheliumderived factor; $P T X-3=$ pentraxin-3. VEGF = vascular endothelial growth factor; VEGFR = VEGF receptor. After Noma et al., 2013.26

Figure 4: Modern Small-incision Vitrectomy Cutter Handpieces with 23-, 25- and 27-Gauge

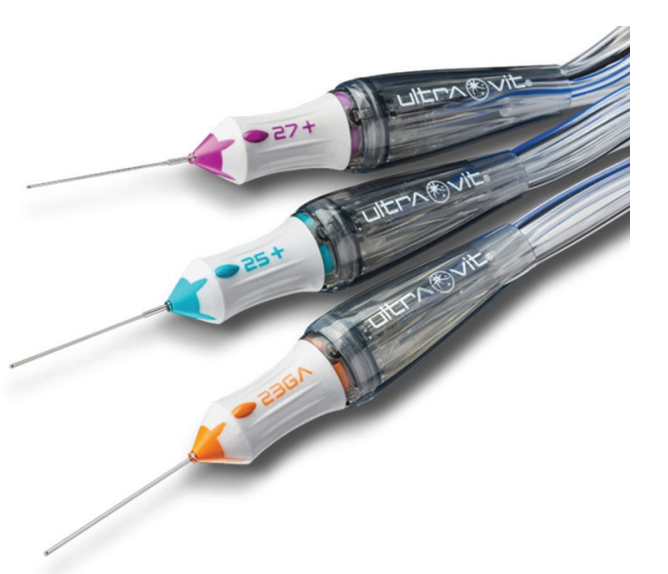

The smallest of them has a diameter of just $0.4 \mathrm{~mm}$ (image provided by the ZEISS company).

developed, ${ }^{29}$ and can be combined with vitrectomy to reduce the load of mediators in the VRI and in the vitreous space.

\section{Oxygen Tension and Vitreoretinal Interface}

As the vitreous gel seems to consume oxygen even under normal conditions in an ascorbate-dependent manner, ${ }^{30}$ this fact may have 


\section{Vitreoretina Editorial}

detrimental effects in case of ischaemic retinopathies such as RVO. In fact, a marked increase in oxygen tension in the VRI after vitrectomy was observed. It can be explained by simple loss of vitreous gel (and ascorbate), by an oxygen increase from the retinal vessels and by the loss of an oxygen gradient and tension regulation..$^{31}$ Therefore, vitrectomy with PVD may produce a higher oxygen tension with possible benefical effects for ischaemic eye diseases. ${ }^{32,33}$

PVD alone has shown to be effective to improve intravitreal oxygen levels in animal models with or without experimental RVO. ${ }^{13,3}$

\section{Conclusion}

Several improved surgical techniques targeting the VRI in different aspects have been emerged and proved durable effects in RVO, especially iatrogenic PVD and modern small-gauge vitrectomy (see Figure 4). However, as in other medical fields, it seems a question of perfect case selection and timing. Finally, much more evidence is required: as the interest in longer-lasting, safe and easy surgical strategies is growing, these procedures must respect and be compared with established standard treatments, such as intravitreal anti-VEGF injections, steroids or laser therapy.
1. Rogers S, McIntosh RL, Cheung N, et al., International Eye Disease Consortium. The prevalence of retinal vein occlusion: pooled data from population studies from the United States, Europe, Asia, and Australia, Ophthalmology, 2010;117:313-9.

2. Wong VK, Retinal venous occlusive disease, Hawaii Med J, 1997;56:289-91. Review

3. Mitchell P, Smith W, Chang A, Prevalence and associations of retinal vein occlusion in Australia. The Blue Mountains Eye Study, Arch Ophthalmol, 1996;114:1243-7.

4. Klein R, Klein BE, Moss SE, Meuer SM, The epidemiology of retinal vein occlusion: the Beaver Dam Eye Study, Trans Am Ophthalmol Soc, 2000;98:133-41; discussion 141-3.

5. Yeh S, Kim SJ, Ho AC, et al., Therapies for macular edema associated with central retinal vein occlusion: a report by the American Academy of Ophthalmology, Ophthalmology, 2015:122:769-78.

6. Khan Z, Almeida DR, Rahim K, et al., 10-Year Framingham risk in patients with retinal vein occlusion: a systematic review and meta-analysis, Can J Ophthalmol, 2013;48:40-5.

7. Heegaard S, Morphology of the vitreoretinal border region, Acta Ophthalmol Scand Suppl, 1997;222:1-31.

8. Mutlu F, Leopold ICH, The structure of human retinal vascular system, Arch Ophthalmol, 1964;71:93-101.

9. Pedler $\mathrm{C}$, The inner limiting membrane oft he retina, Br J Ophthalmol, 1961:45:423-38.

10. Ascaso FJ, Huerva V, Vitreoretinal traction in impending branch retinal vein occlusion: a pathogenetic role? Thromb Haemost, 2012:108:208-9.

11. Hikichi T, Yoshida A, Konno S, Trempe CL, Role of the vitreous in central retinal vein occlusion, Nihon Ganka Gakkai Zasshi. 1996:100:63-8.

12. Takahashi MK, Hikichi T, Akiba J, et al., Role of the vitreous and macular edema in branch retinal vein occlusion, Ophthalmic Surg Lasers, 1997;28:294-9.

13. Quiram PA, Leverenz VR, Baker RM, et al., Microplasmininduced posterior vitreous detachment affects vitreous oxygen levels, Retina, 2007;27:1090-6.

14. Sakuma T, Mizota A, Inoue J, Tanaka M, Intravitreal injection of autologous plasmin enzyme for macular edema associated with branch retinal vein occlusion, Am J Ophthalmol 2010;150:876-82.

15. Tachi $\mathrm{N}$, Hashimoto $\mathrm{Y}$, Ogino $\mathrm{N}$, Vitrectomy for macular edema combined with retinal vein occlusion, Doc Ophthalmol, 1999;97:465-9.

16. Saika S, Tanaka T, Miyamoto T, Ohnishi Y, Surgical posterior vitreous detachment combined with gas/air tamponade for treating macular edema associated with branch retinal vein occlusion: Retinal tomography and visual outcome, Graefes Arch Clin Exp Ophthalmol, 2001:239:729-32.

17. Mandelcorn MS, Nrusimhadevara RK, Internal limiting membrane peeling for decompression of macular edema in retinal vein occlusion: a report of 14 cases, Retina, 2004:24:348-55.

18. Garcia-Arumi J, Boixadera A, Martinez-Castillo V, et al., Radia optic neurotomy in central retinal vein occlusion: compariso optic neurotomy in central retinal vein occlusion: compariso of outcome in young $2007: 143: 134-40$

19. Aggermann T, Brunner S, Krebs I, et al.; ROVO Study Group, A prospective, randomised, multicenter trial for surgical treatment of central retinal vein occlusion: results of the Radial Optic Neurotomy for Central Vein Occlusion (ROVO) study group, Graefes Arch Clin Exp Ophthalmol, 2013;251:1065-72.

20. Kumagai K, Furukawa $\mathrm{M}$, Ogino $\mathrm{N}$, et al., Long-term outcomes of vitrectomy with or without arteriovenous sheathotomy in branch retinal vein occlusion, Retina, 2007;27:49-54.

21. Chung EJ, Lee $\mathrm{H}$, Koh HJ, Arteriovenous crossing sheathotomy versus intravitreal triamcinolone acetonide injection for treatment of macular edema associated with branch retinal vein occlusion, Graefes Arch Clin Exp Ophthalmol, retinal vein occlusion

22. Fuller JJ, Mason JO 3rd, White MF Jr, et al., Retinochoroidal collateral veins protect against anterior segment neovascularization after central retinal vein occlusion, Arch Ophthalmol, 2003;121:332-6.

23. Rehak M, Drechsler F, Koferl P, et al., Effects of intravitreal triamcinolone acetonide on retinal gene expression in a rat model of central retinal vein occlusion, Graefes Arch Clin Exp Ophthalmol, 2011;249:1175-83.

24. Kunikata $H$, Shimura M, Nakazawa T, et al., Chemokines in aqueous humour before and after intravitreal triamcinolone acetonide in eyes with macular oedema associated with branch retinal vein occlusion, Acta Ophthalmol, 2012;90:162-7.

25. Koss MJ, Pfister M, Rothweiler F, et al., Comparison of cytokine levels from undiluted vitreous of untreated patients with retinal vein occlusion, Acta Ophthalmol, 2012;90:e98-e103.

26. Noma H, Mimura T, Eguchi S, Association of inflammatory factors with macular edema in branch retinal vein occlusion, IAMA Ophthalmol, 2013:131:160-5.

27. Bertelmann T, Mennel S, Sekundo W, et al., Intravitrea functional plasminogen is elevated in central retinal vein occlusion, Ophthalmic Res, 2013;50:151-9.

28. Yeh S, Kim SJ, Ho AC, et al., Therapies for macular edema associated with central retinal vein occlusion: a report by the American Academy of Ophthalmology, Ophthalmology, 2015;122:769-78.

29. Gewaily D, Muthuswamy K, Greenberg PB, Intravitreal steroids versus observation for macular edema secondary to central retinal vein occlusion, Cochrane Database Syst Rev, 2015;9.

30. Holekamp NM, Shui YB, Beebe DC, Vitrectomy surgery increases oxygen exposure to the lens: a possible mechanism for nuclear cataract formation, Am J Ophthalmol, 2005;139:302-10.

31. Stefánsson E, Novack RL, Hatchell DL, Vitrectomy prevents retinal hypoxia in branch retinal vein occlusion, Invest ophthalmol Vis Sci, 1990:31:284-9.

32. Murakami T, Takagi $\mathrm{H}$, Ohashi $\mathrm{H}$, et al, Role of posterior vitreous detachment induced by intravitreal tissue plasminogen activator in macular edema with central retinal vein occlusion, Retina, 2007;27:1031-7.

33. Krebs I, Brannath W, Glittenberg C, et al., Posterior vitreomacular adhesion: a potential risk factor for exudative age-related macular degeneration?, Am J Ophthalmol, 2007;144:741-6. 